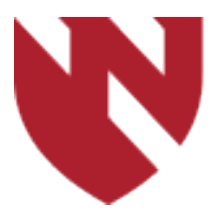

September 2020

\title{
Anesthetic Considerations for Sjogren-Larsson Syndrome
}

\author{
Maireen Miravite \\ University of Nebraska Medical Center \\ Michelle LeRiger \\ University of Nebraska Medical Center \\ Marcellene Franzen \\ University of Nebraska Medical Center \\ Kaitlyn Pellegrino \\ University of Nebraska Medical Center
}

Tell us how you used this information in this short survey.

Follow this and additional works at: https://digitalcommons.unmc.edu/gmerj

Part of the Higher Education Commons, and the Medicine and Health Sciences Commons

\section{Recommended Citation}

Miravite, M., LeRiger, M., Franzen, M., , Pellegrino, K. Anesthetic Considerations for Sjogren-Larsson Syndrome. Graduate Medical Education Research Journal. 2020 Sep 29; 2(1).

https://digitalcommons.unmc.edu/gmerj/vol2/iss1/71

This Conference Proceeding is brought to you for free and open access by DigitalCommons@UNMC. It has been accepted for inclusion in Graduate Medical Education Research Journal by an authorized editor of DigitalCommons@UNMC.For more information, please contact digitalcommons@unmc.edu. 


\section{Anesthetic Considerations for Sjogren-Larsson Syndrome}

Creative Commons License

(c) (i) ()

This work is licensed under a Creative Commons Attribution-Noncommercial-No Derivative Works 4.0 License. 
only 3 reached statistical significance (IL-10, IP-10, TNF $\alpha$ ), and none were significantly greater in OA vs. RA.

Conclusion: Although this commercially available multiplex assay generally performed well in the context of RA, interference induced by RF meaningfully impacted the quantification of one in five analytes examined.

https://doi.org/10.32873/unmc.dc.gmerj.2.1.066

\section{Running Miles Without the Smiles; an Exploration of Alternative Treatment \\ Peter M. Martin ${ }^{1}$, Rebecca L. Peebles ${ }^{1}$}

${ }^{1}$ University of Nebraska Medical Center, Department of Family Medicine and Offutt Airforce Base

Mentor: Rebecca L. Peebles

Program: Family Medicine

Type: Case Report

Background: A 42-year-old male presented to sports clinic with bilateral anterolateral lower leg pain for 1.5 years. Pain is exacerbated by running with associated painful swelling and "small bulges" along the anterolateral legs. Symptoms arise within 8 minutes of activity and cease within 5-10 minutes of rest. Physical therapy was unsuccessful.

\section{Methods:}

- Bilateral Lower Extremity Exam:

»Inspection: Normal

» Palpation: Normal

»ROM: Normal

» Special Tests: Resisted ROM testing and tuning fork exam normal

- Bilateral LE X-ray and MRI: normal

»Compartment Pressure Testing: See Table 1

» Elevated post-exercise compartment pressures noted

»With exercise, $2 \mathrm{~cm}$ tender bulge present on lateral lower legs bilaterally
Results: The patient's final diagnosis was bilateral chronic exertional compartment syndrome (CECS) with associated fascial hernias. After counseled on treatment options including gait retraining, botulinum toxin injections, and fasciotomy, he received 50 units botulinum toxin at each legs' anterior and lateral compartments. Within 3 weeks he reported $70 \%$ improvement and later completed gait retraining without pain.

Conclusion: Lower extremity fascial hernias may present with or without CECS symptoms. CECS is reversible, exercise induced ischemia at a predictable level of exercise due to noncompliant osseofascial compartments. Numerous cases support botulinum toxin injections for CECS, but little evidence exists for its use in fascial hernias. This sparks the question if compartment testing and botulinum toxin treatment should be considered for all fascial hernias, including those without CECS symptoms. With physical therapy and gait retraining, this offers an alternate approach to fasciotomy.

https://doi.org/10.32873/unmc.dc.gmerj.2.1.067

\section{Table 1.}

Compartment testing before and after exercise (in $\mathrm{mm} \mathrm{Hg}$ ).

\begin{tabular}{lcccc} 
& $\begin{array}{c}\text { Pre-Exercise } \\
\text { Left Leg }\end{array}$ & $\begin{array}{c}\text { Post-Exercise } \\
\text { Left Leg }\end{array}$ & $\begin{array}{c}\text { Pre-Exercise } \\
\text { Right Leg }\end{array}$ & $\begin{array}{c}\text { Post-Exercise } \\
\text { Right Leg }\end{array}$ \\
\hline Anterior & 11 & 81 & 12 & 30 \\
\hline Lateral & 18 & 35 & 17 & 22 \\
\hline Deep Posterior & 7 & 26 & 6 & 7 \\
\hline Superficial Posterior & 13 & 19 & 10 & 20 \\
\hline
\end{tabular}

\section{Anesthetic Considerations for Sjögren-Larsson Syndrome \\ Maireen Miravite ${ }^{1}$, Michelle LeRiger ${ }^{1}$, Marcellene Franzen ${ }^{1}$, Kaitlyn Pellegrino}

${ }^{1}$ University of Nebraska Medical Center, Department of Anesthesiology

Mentor: Michelle LeRiger, Marcellene Franzen, Kaitlyn Pellegrino

Program: Anesthesiology

Type: Case Report

Background: Sjögren-Larsson syndrome (SLS) is a rare autosomal recessive neurocutaneous disorder caused by a mutation in the gene encoding fatty aldehyde dehydrogenase. SLS is characterized by eneralized ichthyosis, seizures, cognitive disability, spasticity, and ophthalmologic changes. Limited resources are available to guide anesthetic management for patients with SLS. This case series seeks to identify anesthetic considerations in patients with SLS.

Methods: After IRB approval, a chart review of anesthetic records of SLS patients from February 2013 to October 2019 was conducted. Data included age, gender, relevant comorbid conditions
(Table 1), induction and maintenance agents, intravenous and oral analgesics, muscle relaxants, procedure performed, and complications.

Results: A total of 14 patients undergoing 47 anesthetic cases were identified. Cases included brain MRI, botulinum toxin injection, tendon release, and dental restoration. General anesthesia was performed for nearly all procedures. The most common observations were related to ichthyosis, including difficulty 


\section{Table 1.}

Patient demographics and clinical characteristics.

\begin{tabular}{|c|c|c|}
\hline & $\begin{array}{c}\text { By Case }(n=47) \\
N(\%)\end{array}$ & $\begin{array}{c}\text { By Patient }(n=14) \\
N(5)\end{array}$ \\
\hline \multicolumn{3}{|l|}{ Gender } \\
\hline Male & $17(36.1)$ & $5(35.7)$ \\
\hline Female & $30(63.8)$ & $9(64.6)$ \\
\hline \multicolumn{3}{|l|}{$\mathrm{Age}^{1}$} \\
\hline $0-5$ & $19(40.4)$ & \\
\hline $6-10$ & $6(12.7)$ & \\
\hline $11-15$ & $11(23.4)$ & \\
\hline $16-20$ & $8(17)$ & \\
\hline $21+$ & $3(6.4)$ & \\
\hline Average & Mean $10 y$ & \\
\hline \multicolumn{3}{|c|}{ Clinical Characteristics } \\
\hline Seizure history² & & $5(35.7)$ \\
\hline Contractures & & $14(100)$ \\
\hline Photophobia & & $6(42.8)$ \\
\hline $\begin{array}{l}\text { Able to } \\
\text { ambulate }\end{array}$ & & $10(71.4)$ \\
\hline \multicolumn{3}{|l|}{$\mathrm{IQ}^{3}$} \\
\hline$\leq 50$ & & $7(50)$ \\
\hline$>50$ & & $6(42.8)$ \\
\hline Mean $=55$ Medi & $\operatorname{ian}=50.5$ & \\
\hline
\end{tabular}

with adherence of monitors and skin tearing upon removal of adhesives. Other complications were patient specific and not related to SLS.

Conclusion: Patients with SLS typically require general anesthetics when undergoing diagnostic studies and procedures for symptom management. Our case series suggests that general anesthesia is well tolerated in this population. Important aspects of pre-anesthetic evaluation include history of seizure severity and control, neurocognitive assessment and skin examination. Intraoperative considerations include photophobia, difficulty securing PIVs and monitors, relative heat intolerance, hypohydrosis, and challenges with positioning, padding, and line placement due to contractures. The ichthyosis of SLS spares the midface eliminating difficulty in securing airway devices.

https://doi.org/10.32873/unmc.dc.gmerj.2.1.068

\section{Double Umbilical Cord Blood Transplantation in a Pediatric Patient: A First for Nebraska Grace Murray ${ }^{1}$, Sachit Patel ${ }^{1}$}

${ }^{1}$ University of Nebraska Medical Center, Department of Pediatrics

Mentor: Sachit Patel

Program: Pediatrics

Type: Case Report

Background: Unrelated umbilical cord blood (UCB) transplantation has been used as a hematopoietic stem cell source for 30 years. Compared to adult bone marrow and peripheral blood stem cells, UCB has more rapid availability, absence of donor attrition, and reduced risk of GVHD despite HLA disparity. Unfortunately for larger patients, a single UCB unit has an insufficient amount of total nucleated cells to support engraftment. The use of two well-matched UCB units has been shown to overcome this barrier.
Methods: Chemotherapy, Graft, Cord Blood Transplant. Consent was obtained to utlize this case for educational purposes.

Results: A 12 year-old presented with bleeding and weight loss and was found to have anemia, thrombocytopenia and leukocytosis. Peripheral smear demonstrated auer rods. He was diagnosed with acute myeloid leukemia (AML-M4). He successfully completed therapy with protocol AAML 1031 but relapsed seven months later. He achieved a second complete remission with protocol AAML 0523. Given his high risk disease and poor prognosis with chemotherapy alone, the patient was offered transplant. No suitable sibling or adult unrelated donors were found. He underwent mismatched double umbilical cord transplant. Complications included grade III aGVHD involving the skin and GI system, and CMV reactivation. Engraftment was achieved on day +27 . He is now 16 years-old with full donor chimerism and complete immune reconstruction, no findings of chronic GVHD and no disease relapse.

Conclusion: This was the first pediatric patient in Nebraska to have a successful double UCB transplant. Double cord transplant is an acceptable alternative when there is no sibling or unrelated donor match and when a single cord unit total nucleated dose is insufficient.

https://doi.org/10.32873/unmc.dc.gmerj.2.1.069

\section{Shwachman-Diamond Syndrome: First Successful Hematopoietic Stem Cell Transplant in Nebraska Grace Murray ${ }^{1}$, Sachit Patel ${ }^{1}$}

${ }^{1}$ University of Nebraska Medical Center, Department of Pediatrics

Mentor: Sachit Patel

Program: Pediatrics

Type: Case Report
Background: Shwachman-Diamond syndrome (SDS) is an autosomal recessive condition characterized by bone marrow dysfunction, pancreatic insufficiency, and skeletal abnormalities. Ninety percent of patients with SDS have a mutation in the SBDS gene on chromosome 7, while the other ten percent are diagnosed clinically. 